\title{
Determinants of university participation in EU R\&D cooperative projects
}

Citation for published version (APA):

geuna, A. (1996). Determinants of university participation in EU R\&D cooperative projects. MERIT, Maastricht Economic Research Institute on Innovation and Technology. MERIT Research Memoranda No. 007 https://doi.org/10.26481/umamer.1996007

Document status and date:

Published: 01/01/1996

DOI:

10.26481/umamer.1996007

Document Version:

Publisher's PDF, also known as Version of record

\section{Please check the document version of this publication:}

- A submitted manuscript is the version of the article upon submission and before peer-review. There can be important differences between the submitted version and the official published version of record. People interested in the research are advised to contact the author for the final version of the publication, or visit the DOI to the publisher's website.

- The final author version and the galley proof are versions of the publication after peer review.

- The final published version features the final layout of the paper including the volume, issue and page numbers.

Link to publication

\footnotetext{
General rights rights.

- You may freely distribute the URL identifying the publication in the public portal. please follow below link for the End User Agreement:

www.umlib.nl/taverne-license

Take down policy

If you believe that this document breaches copyright please contact us at:

repository@maastrichtuniversity.nl

providing details and we will investigate your claim.
}

Copyright and moral rights for the publications made accessible in the public portal are retained by the authors and/or other copyright owners and it is a condition of accessing publications that users recognise and abide by the legal requirements associated with these

- Users may download and print one copy of any publication from the public portal for the purpose of private study or research.

- You may not further distribute the material or use it for any profit-making activity or commercial gain

If the publication is distributed under the terms of Article $25 \mathrm{fa}$ of the Dutch Copyright Act, indicated by the "Taverne" license above, 


\title{
Determinants of University participation in EU R\&D Cooperative Projects*
}

\author{
by \\ Aldo Geuna \\ MERIT, University of Limburg
}

First Draft: February 1995

This Draft: April, 1996

* The useful comments and suggestions of Cristiano Antonelli, Anthony Arundel, Alfonso Gambardella, Paul David, Ed Steinmueller and Katy Wakelin are gratefully acknowledged, as well as the financial support of the European Union Human Capital and Mobility Program, Contract Nr. ERB4050PL930320. 


\section{Introduction}

In the course of implementing the succession of Framework Programmes EU's research and development policy has advanced in budgetary scope. An enlarged number of institutions are taking part in $\mathrm{R} \& \mathrm{D}$ cooperative projects funded by the European Commission. In the Third Framework Programme the institutions classified under the label of Higher Education Institutions (HEIs), almost exclusively universities, are the largest single type of institution in terms of the number of participations.

The increasing participation of HEIs in each successive Framework carries important consequences both for the funding structure of universities and for the process of network formation and internationalization of research. Consider, for example, the situation in the UK. When we compare funding for each university from European Community sources and from research grants and contracts of the Research Councils in 1992-1993, we find that, on average, European Community funds are $21 \%$ of Research Councils funds, but for about $10 \%$ of the institutions they represents more than $50 \%$. When we look at indicators of the dynamics of knowledge production, they show a more internationalized process, reflecting the internationalization of network structure. ${ }^{1}$ Framework Programmes represent a suitable vehicle to develop or reinforce linkages for a more extensive European Research network. Thus, the participation in EU R\&D cooperative projects may have important impacts on the future research potentialities of the participants ${ }^{2}$.

The purpose of this paper is to study which are the factors that influence university participation in EU R\&D cooperative projects. In particular, we analyse the relevance for university participation of: a) the characteristics and behaviour of the universities, b) the behaviour of the funding agency, and c) the un-intended consequences of the selection mechanisms for allocating funds. The unit of analysis can vary from the most disaggregate level of the research group to the entire institution. For the present study, we develop a cross country analysis at the university level. ${ }^{3}$ To generate an unbiased unalysis, the availability of information on the reference population is extremely important. In our case is possible to consider the totality of recognized European universities as the total population. We constructed a data-set including the total population of European universities. On the top of institutional information we gathered the number of times each university took part in a R\&D cooperative project in the First, Second and Third Framework Programmes. On the basis of this original data-set, we formulate an

\footnotetext{
1 For the development of international scientific collaboration see among others Luukkonen et al. (1992).

2 For the continuation of cooperation after the end of the project see AXION (1995).

3 For the reasons of this choice see Section 3.
} 
empirical model to test for the relevance of different factors on both the probability of joining a EU R\&D project and the actual number of participations in projects.

This study has to be understood in the framework of the analysis of resource allocation criteria. ${ }^{4}$ Together with the papers of Gambardella and Garcia-Fontes, and Garcia-Fontes and Geuna published in this collection, it represents the first output of a larger research programme for understanding the institutional mechanisms and resource allocation criteria characterizing publicly financed research.

The paper is organized as follows. In Section 2 we discuss the increasing participation of HEIs in cooperative R\&D projects of the Community Framework Programmes. In Section 3, after the presentation of the unit of analysis and the description of the data-set, we introduce the factors that may influence university participation in EU R\&D projects. The econometric model and the interpretation of the results are offered in Section 4. Finally, in Section 5 policy implications and conclusive remarks are put forward.

\section{HEI participation in Community Programmes}

Recent efforts of the European Union to establish a targeted programme for improving industrial competitiveness through the mechanism of funded research officially began with the First Framework Programme (1984-1987). The Framework was set up with the goal of strengthening strategic areas of European competitiveness. The mechanisms selected for the Framework included a) funding the R\&D effort of private firms, research institutes, higher education institutes ${ }^{5}$ in the strategic areas, and b) attempting to allocate funding to stimulate the formation of research networks spanning organizational and national boundaries. With the Second Framework Programme (1987-1991) the Community decided to use the Framework as "..the basis and instrument of European research and technology policy....thus providing a clear structure for long term overall objectives". ${ }^{6}$ A comprehensive political strategy on technology, enjoying equal status with other key Community policy areas, was set. The Third Framework Programme (1990-1994) is characterized by the regrouping of activities around only three strategic areas with 15 separate programmes and by the reinforcement of the aim of convergence

\footnotetext{
4 See for example Dasgupta and David (1994), David (1994), Arora, David and Gambardella (1995).

5 The Community reimburses up to $50 \%$ of project actual costs to companies or research institutes, and to universities and other higher education establishments it reimburses the $100 \%$ of additional costs.

${ }^{6}$ See Commission of the European Communities, 1992, EC Research Funding. A guide for Applicants.
} 
among the member states of the EU. ${ }^{7}$ Lastly, the Fourth Framework Programme (1994-1998) pursues the guide lines of the previous one, putting more emphasis on the consistency between national and Community policy.

Table 1: $\quad$ The Framework Programmes.

\begin{tabular}{||l|c|c||}
\hline Programme & Duration & EU Contribution \\
\hline First Framework Programme & $1984-1987$ & 3.750 MECUs \\
\hline Second Framework Programme & $1987-1991$ & 5.396 MECUs \\
\hline Third Framework Programme & $1990-1994$ & 6.600 MECUs \\
\hline Fourth Framework Programme & $1994-1998$ & $12.300^{*}$ MECUs \\
\hline
\end{tabular}

Sources: Commission of the European Communities (1994).

${ }^{*}$ It includes activities that were not encompassed in the other Frameworks.

In the course of implementing the succession of Frameworks, EU's research and technological development policy has advanced in budgetary scope, as is illustrated in Table 1, and has developed a few key goals. In particular, the total budget of the Fourth Framework is more than three times that of the first in nominal value. Moreover, in the last ten years the main aims of EU's research and technological development policy have been clearly defined. Of particular importance are the following three (CEC, 1992; p.8):

i) Stimulus to "cross-border cooperation, coordination, and mobility between industry and science" to realize a scientific and technological cohesion among the European countries;

ii) Support to "basic research...for which medium-sized companies frequently do not have the necessary personnel or capital";

iii) Harmonization of "research and technology into the concept of completing the single internal market in Europe".

7 As is clearly stressed in Commission of the European Communities (1992; p.11), "...where projects are evenly matched in qualitative terms, preference will be given to projects involving participants from technologically less well developed regions." 
Table 2: $\quad$ Distribution of participations (a) and funding (b), by organizational type: $2^{\text {nd }}$ and $3^{\text {rd }}$ Framework Programmes.

\begin{tabular}{||l|r|r|r|c||}
\hline \hline $\boldsymbol{B I G}$ & $\begin{array}{c}\mathbf{a}(\%) \\
2^{\text {nd }}\end{array}$ & $\begin{array}{c}\mathbf{a}(\%) \\
3^{\text {rd }}\end{array}$ & $\begin{array}{c}\mathbf{b}(\%) \\
2^{\text {nd }}\end{array}$ & $\begin{array}{c}\mathbf{b}(\%) \\
3^{\text {rd }}\end{array}$ \\
\hline $\boldsymbol{S M E}$ & 21.9 & 17.2 & 41.1 & 30.0 \\
\hline $\boldsymbol{R E C}$ & 18.1 & 17.6 & 18.7 & 21.1 \\
\hline $\boldsymbol{H E I}$ & 29.5 & 30.3 & 20.8 & 23.2 \\
\hline Other & 29.2 & 31.5 & 18.9 & 21.8 \\
\hline
\end{tabular}

Source: David, Geuna and Steinmueller (1995).

The European Commission classifies the institutions that participate in the Framework Programmes in one of five categories: Big Companies (BIG), Small and Medium Enterprises (SME), Public or Private Research Centres (REC), Higher Education Institutions (HEI) and Others. In Table 2 we have shown the distribution of the five types of institutions in terms of (a) number of participations and (b) funding for shared cost action for the Second and Third Framework Programme. ${ }^{8}$ Three main observations emerge from this table. First, Big Companies have suffered a decrease between the Second and Third Framework both in the number of participations and in their funding. Most of the 11 percentage point cut in Big Companies' funding was redistributed to "research institutions", public or private research centres and higher education, with the result that the latter institutions' funding approached $50 \%$ in the Third Framework Programme, up from 40\% during the Second Framework. Second, the share of HEIs has increased, reaching a bit less then one third (31.5\%) of the total number of participations. Universities, almost the totality of HEIs, as we will show in the following sections, are then the largest single type of institution in terms of the number of participations. Third, in both periods "research institutions" have a markedly higher share of participations than their share of funds. This means that funds are more thinly spread, on average, across participating units in the research centres and higher education community than among participating businesses. For HEIs, the difference in share of participation and funding shrank between the Second and Third Framework Programmes, but still remained about ten percentage points.

HEIs play an important role in the EU's research and technological development policy. On the one hand, they are supplying basic knowledge needed by business enterprises, and, on the

\footnotetext{
${ }^{8}$ For the Third Framework Programme the figure refers to circa the $85 \%$ of the contracts.
} 
other hand, they are benefitting from gaining access to complementary expertise and instrumentation in Big Companies' R\&D laboratories. Moreover, for HEIs, participation in a Framework project means not only access to EU funding, but also the opportunity to interact with industry and other research organizations in the formation of new, high quality research networks. This is extremely important, especially for those countries with lower scientific and technological resources, because it enables such countries to overcome the constraints imposed by the small size of their research community.

Table 3: $\quad$ Collaborative links involving HEI and REC, by Framework.

\begin{tabular}{||l|l|l|l|l||}
\hline \multirow{2}{*}{ Organization type } & \multicolumn{2}{|c|}{$\mathbf{2}^{\text {nd }}$ Framework } & \multicolumn{2}{c||}{$\mathbf{3}^{\text {rd }}$ Framework } \\
\hline & HEI & REC & HEI & REC \\
\hline HEI & $25.6 \%$ & $36.0 \%$ & $29.8 \%$ & $42.4 \%$ \\
\hline REC & $36.7 \%$ & $28.6 \%$ & $40.6 \%$ & $28.5 \%$ \\
\hline BIG & $19.6 \%$ & $18.5 \%$ & $14.8 \%$ & $14.1 \%$ \\
\hline SME & $16.6 \%$ & $15.4 \%$ & $12.1 \%$ & $12.1 \%$ \\
\hline Other & $1.5 \%$ & $1.5 \%$ & $2.7 \%$ & $3.1 \%$ \\
\hline
\end{tabular}

Source: David, Geuna and Steinmueller (1995).

In Table 3 we have shown the evolution of collaborative links by organization type for HEIs and RECs. In moving from the Second to the Third Framework programmes, the number of HEIs' links with other HEIs and with research centres, both increased. $29 \%$ of their links are still with industrial partners. The number of links are affected by the increasing numbers of HEIs and RECs participating in the framework. Despite this increase, university-industry collaborations remain important in the Third Framework. When we consider the total number of collaborative links, we can identify three relevant groups. First, the industrial group --i.e. collaborative links BIG-BIG, SME-SME and BIG-SME-- with about $30 \%$ and $19 \%$ of the links in the Second and Third Frameworks respectively. Second, the research group --i.e. collaborative links HEI-HEI, REC-REC and HEI-REC-- which have not only the largest but also an increasing share of links, circa 39\% and 50\%. Third, the hybrid group --i.e. collaborative links across the institutions of the two previous groups-- with about $30 \%$ and $27 \%$ of the links respectively. The cooperation between "research institutions" and industry, characteristic of the hybrid group, although decreasing is nonetheless significant part of the picture.

Finally, we have looked at the EU contractual funding across different programmes for HEIs. On the one hand, when we consider the share distribution for each programme by type of 
participant we identify a group of programmes in which HEI have about $50 \%$ of the funds. They are Step/Epoch, Bridge and Science And Technology For Development, ${ }^{9}$ in the Second Framework, and Environment, Marine Science And Technology, Biotechnology and Life Sciences And Technologies For Developing Countries, in the Third Framework. On the other hand, when we focus on the share distribution for each type of participant by programme the previous group of university-oriented programmes loses importance. The two industriallyoriented programmes, Esprit and Brite-Euram, and their continuations under the Third Framework Programme, are always the most important sources of HEI funding. ${ }^{10}$

At the end of the Third Framework Programme HEIs are the largest single type of institution in terms of the number of participations. They have developed collaborative links especially with other research institutions, taking nonetheless part in an important number of projects with industrial partners. Finally, although they are the dominant player in a few Framework Programmes particularly oriented towards HEIs, they are also present with a relevant share in the industrially-oriented programmes.

The previous analysis enables us to highlight four main observations. First, if the financial trend of the Third Framework Programme is continued in the Fourth Framework Programme, ${ }^{11}$ the distribution of funds by type of participant will tend to become homogeneous across the groups. Second, the increasing share of HEI, within a Framework Programme characterized by a growing budget, implies a more important impact of EU funds on the higher education finance system. In particular, in a period of budget cuts, restructuring and internationalization of the European higher education system, the availability of a new competitive source can have extremely important consequences. ${ }^{12}$ Third, the growing budget of the Framework Programme represents a vital opportunity for institutions in countries with little resources to overcome the constrains imposed by the small size of the national research community. Forth, in the course of the three Framework Programmes HEI have developed varied ways to draw upon the EU funds. They have joined cooperative project that range from grant to university consortia for basic research to university/industry cooperation in marketoriented research.

\footnotetext{
9 We do not take into account the programmes under the heading Improvements To European Scientific And Technological Cooperation due to their specific character.

10 Only Environment, among the programmes of the previous group, receives in absolute terms a relevant share of funds $(16 \%)$.

11 As the Fourth Framework Programme pursues the guide lines of the previous one and as we can presume consistency in the policy behaviour of the Commission one may expect that the trend will be confirmed.

12 Impact and unintended effects of EU funding upon the allocation of national public and private research funding going to higher education institutions --i.e. university departments-- in UK are discussed in David, Geuna and Steinmueller (1995; pp. 32-42).
} 
Having stated that, it becomes crucial to understand why some universities and other post secondary education institutions are taking part with different frequency in cooperative projects within the EU Framework Programme. In the next section, after the presentation of the unit of study and the description of the data-set, we shall focus our analysis on the understanding of the determinants of university participation in EU R\&D cooperative projects. Then, in Section 4, we shall estimate an econometric model for university participation.

\section{University participation in EU R\&D cooperative projects}

The total HEI population in the $\mathrm{EU}^{13}$ was circa 1427 institutions in 1990-92. Of these, 381 were universities, 39 new universities ${ }^{14}$ (NU) and 1007 Post Secondary Institutions (PSI). In Table 4 we have shown the count and share of universities and HEIs (Universities+NU+PSI), broken down by EU country.

Table 4: $\quad$ Count and share of universities and HEIs, by country

\begin{tabular}{||l|l|l|l|l|l|l|l|l|l|l|l|l||}
\hline \hline & $\mathrm{B}$ & $\mathrm{Dk}$ & $\mathrm{F}$ & $\mathrm{G}$ & $\mathrm{Gr}$ & $\mathrm{I}$ & $\mathrm{Ir}$ & $\mathrm{NL}$ & $\mathrm{P}$ & $\mathrm{S}$ & $\mathrm{UK}$ & TO \\
\hline UNIV & 15 & 7 & 73 & 75 & 15 & 47 & 7 & 13 & 18 & 40 & 71 & 381 \\
\hline$\%$ & 4.0 & 1.8 & 19.2 & 19.7 & 4.0 & 12.3 & 1.8 & 3.4 & 4.7 & 10.5 & 18.6 & 100 \\
\hline HEIs & 74 & 41 & 535 & 270 & 17 & 69 & 34 & 32 & 57 & 48 & $250^{*}$ & 1427 \\
\hline$\%$ & 5.2 & 2.9 & 37.5 & 18.9 & 1.2 & 4.8 & 2.4 & 2.2 & 4.0 & 3.4 & 17.5 & 100 \\
\hline
\end{tabular}

${ }^{*}$ The UK value is an estimate.

We have classified an institution in the category university following the official national classification. Two other main sources of information have been used: 1) the International Handbook of Universities (1991, 1994), and 2) the World of Learning (1995). When discrepancies between the sources were found, we have classified an institution in the category university if that institution was entitled to grant a doctoral (Ph.D) degree. In a few cases, mainly in Spain and Portugal, we did not take into account the most recent and not yet developed universities. When clearly distinguishable Art, Physical Education, and Education schools were

\footnotetext{
13 We do not take into account Luxembourg.

14 The class new universities refers to the 39 UK Polytechnics and Colleges that have been granted university status in 1992-93. As they were mainly teaching institutions, it is important to differentiate them from the other UK universities.
} 
excluded. ${ }^{15}$ The three institutions Universitair Centrum Antwerpen, Universitaire Faculteiten Sint-Ignatius te Antwerpen and Universitaire Instelling Antwerpen have been subsumed under the hat of the University of Antwerp. Finally, to calculated the number of UK universities we have made use of information of the Universities' Statistical Record. The resulted value of 73 is due to fact that the University of Cambridge and the University of Oxford are considered as one institution, the University of London is subdivided into 22 colleges, and the three institutions Manchester Business School, Manchester University and UMIST have been subsumed in the University of Manchester.

In Europe there is no standardization on the definition of PSI and University. In the different countries these terms carry varying connotations. However, in all the EU countries, the institutions that have been granted the university status went through a national selection process that can be considered more stringent then the one for the granting the PSI status. Therefore, this category can be considered more homogeneous. Moreover, large part of PSIs are mostly teaching oriented institutions, then not involved in research. Those that are involved in research are generally more oriented towards regional or national type of networking. Only when their scientific research quality is extremely high they are trying to access the EU funding system. Thus, in the following analysis we shall focus our attention only on universities.

The ideal unit of analysis to understand university participation in EU R\&D project would be the research group/research centre that applied for EU founds. This information is currently not available at the cross country level. Although less informative, we have decided that was worthwhile to analyse university participation in EU R\&D cooperative projects at the aggregate level of the university. Clearly, this unit of analysis has a dimensional bias. Large universities tend to have more research groups and consequently tend to participate more in EU projects. Nonetheless, we think that, given the dimension, other factors such as scientific research quality, geographical localization, scientific orientation are useful to explain the participation in EU projects. Moreover, the analysis at the institutional level has independent justifications. First, although the literature on R\&D cooperation emphasises the centrality of the research group, we believe that, particularly in this special case of international cooperation, the identity of the institution --i.e. Cambridge University versus De Montfort University-- plays an important role. In particular, because the funding agency --i.e. the European Commission-- is not perfectly informed, the institutional reputation or "the name" of the institution becomes a substitute for missing information on specific researchers or research groups. Second, to develop an international cooperation with a well known university means also to originate positive image externalities for the institution involved. The literature recognizes in the augmented image and

\footnotetext{
15 In most of the countries this schools are not included in the university category. In the few cases in which they have university status, we chose to exclude them.
} 
prestige due to the link one of the main incentives for a cooperation. ${ }^{16}$ Then, again, the institution itself comes to the fore. Third, taking the university as unit of analysis enables us to have information on the total population --i.e. both the universities that have joined EU R\&D projects an the ones that did not have taken part in them-- and consequently our analysis will not have any selection bias. Forth, from a methodological point of view, the macro analysis at the institution level enables us to draw the background picture of this particular area of R\&D cooperation. In future research, the micro analysis at the research group level will be carried out on the basis of the results of the current work.

\section{Figure 1: Decision Tree for Initiation of Cooperative Agreement}

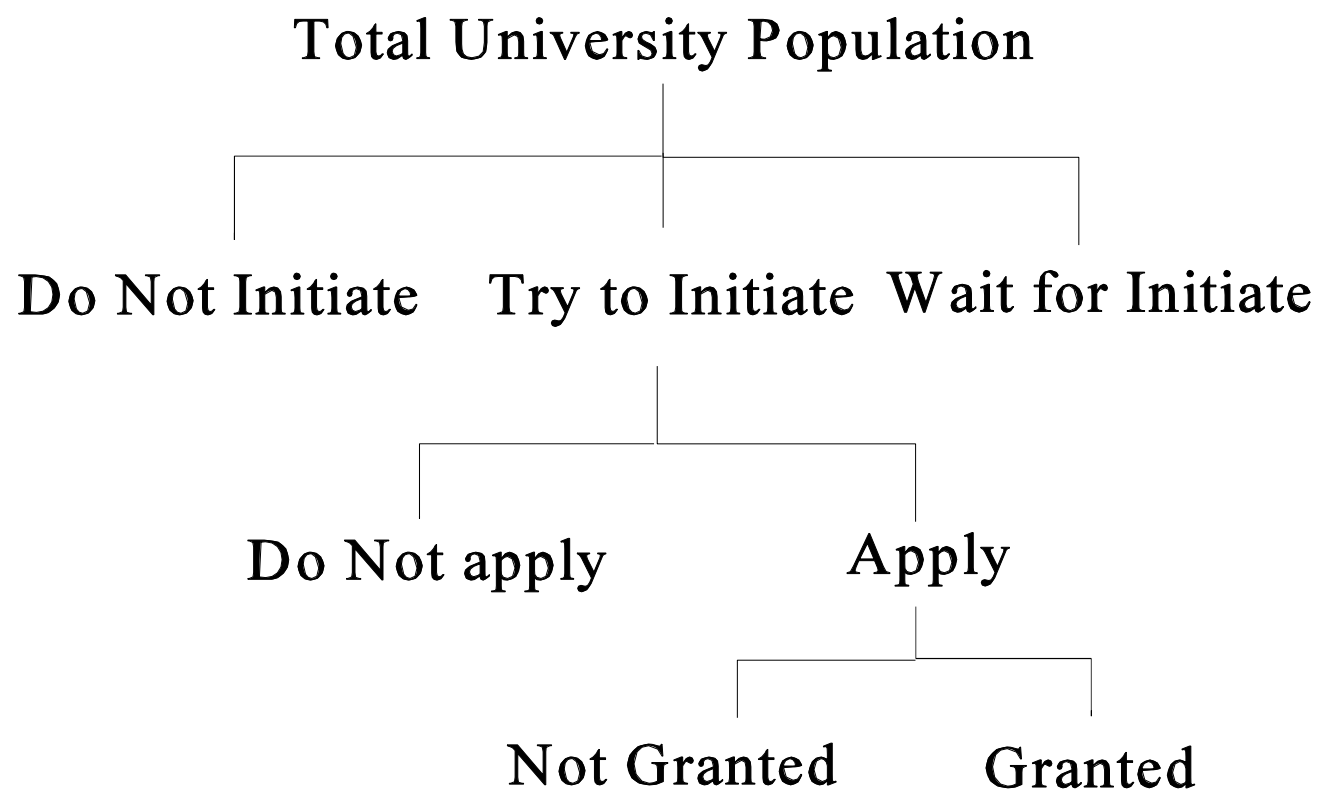

Universities participating in EU R\&D projects are a sub-group of all universities that applied for EU funds, while the ones that applied are a sub-set of all universities that tried to initiate a cooperative project. In addition, some universities did not try to initiate a cooperative agreement and others have not made a decision because they did not have information or they were uncertain on what to do. These different groups constitute the total population of universities in Europe (Figure 1).

16 See for example Malerba et al. (1991). 
At present, we have gathered the data concerning the universities that have been involved in a $R \& D$ project (granted), and the total university population. The analysis of this information will enable us to highlight some of the factors affecting university participation in cooperative projects within the EU Framework Programme.

We obtained the original data from the DG XII -i.e. Directorate-General Science, Research and Development-- of the European Commission. They refer only to shared-cost actions funded by the DG XII under the First, Second and Third Framework Programmes. ${ }^{17}$ However, the data for the First Framework Programme are not complete because the database of the DG XII has been created only after the end of the programme, then only a part of the data concerning the First Framework Programme have been stored in it. Moreover, the information for the Third Framework Programme is only up to 15/3/1994. For each university we were provided with geographical information and with the Number of Contract Partner Links. The latter represents the number of times a HEI has been involved in a R\&D project. That is to say, the number of participations for each institutions No time or programme information were released to us. The database constructed in this way comprises 330 universities, they represent $86 \%$ of the total population of European universities.

For the total population of European universities, on the top of the geographical information and of the number of times a university has been involved in a EU R\&D project (PART), we have gathered the following data:

NRES: $\quad$ The number of researchers ${ }^{18}$ in 1992. Used as a proxi for the dimension of the universty.

PUBS: $\quad$ The number of papers published by a scholar associated to a specific institution in $1993 .^{19}$ In the case of one author the count is one, while in the case of co-

\footnotetext{
17 In both the Second and the Third Framework the research concerned with information and communications technologies was under the supervision of DG XIII, therefore it is not included in the data set. Some other small programmes directed by DG VI, DG XIII and DG XIV are not included too. Still, about $55 \%-60 \%$ of the funds were administered by DG XII therefore, even if biased, we have a quite relevant sample.

18 The number of researchers includes the totality of full-time academic staff plus, when present, $50 \%$ of part-time academic staff.

19 For the analysis of all the problems connected with the data collection see CEC (1994; pp.38-40). Special mention must be made of the peculiar role played by hospitals. Their weight in the presence count is not just overestimated because of the effect of co-authorship, it is also often unclear whether they are linked to the university or not. Then in some cases the publication is counted as university and other as hospital. This varies among the European countries due to the widespread institutional variety.
} 
authorship the count is equal to the number of the authors. The data source is the Science Citation Index, CD-ROM version 1993, ISI. $^{20}$

RATIO: The ratio between the number of publications and the number of researchers (PUBS/NRES). Used as a proxi for the scientific research quality of the university.

FIELDS: The scientific fields in which the institution grants a doctoral degree. These are converted into a categorical variable to classify the institutions in relation to their scientific field orientation.

NEWOLD: The institutions' founding year. This has been turned into a categorical variable to classify the institutions in relation to their historical age.

Table 5: $\quad$ Descriptive statistics for the main variables (TP=Total Population; P=Participants; NP=Non-Participants).

\begin{tabular}{||l|c|c|c|c|c|c|c|c|c|c|c|c||}
\hline \hline Var & \multicolumn{4}{|c|}{ Mean } & \multicolumn{3}{c|}{ Std. dev } & \multicolumn{3}{c|}{ Min } & \multicolumn{4}{c||}{ Max } \\
\hline & $\mathrm{TP}^{1}$ & $\mathrm{P}^{2}$ & $\mathrm{NP}^{3}$ & $\mathrm{TP}$ & $\mathrm{P}^{2}$ & $\mathrm{NP}^{3}$ & $\mathrm{TP}^{1}$ & $\mathrm{P}^{2}$ & $\mathrm{NP}^{3}$ & $\mathrm{TP}^{1}$ & $\mathrm{P}^{2}$ & $\mathrm{NP}^{3}$ \\
\hline PART & 49 & 56 & 0 & 65 & 66 & 0 & 0 & 1 & 0 & 420 & 420 & 0 \\
\hline NRES & 887 & 922 & 631 & 946 & 896 & 1232 & 15 & 36 & 15 & 7330 & 7000 & 7330 \\
\hline PUBS & 415 & 461 & 84 & 519 & 530 & 258 & $5^{*}$ & $5^{*}$ & $5^{*}$ & 3185 & 3185 & 1397 \\
\hline RATIO & 0.568 & 0.636 & 0.078 & 0.971 & 1.016 & 0.142 & 0.005 & 0.005 & 0.005 & 12.34 & 12.34 & 0.598 \\
\hline
\end{tabular}

* Estimate value; ${ }^{1} 371$ valid cases; ${ }^{2} 326$ valid cases; ${ }^{3} 45$ valid cases. Ten cases have been excluded due to missing data.

In Table 5 we have shown the descriptive statistics for the four continuous variables. 326 universities (four cases have been excluded due to missing data) have participated from a minimum of 1 time to a maximum of 420 times in a cooperative project. They have participated on average in 56 projects. The high Kurtosis (5.536) and the positive Skewness (2.130), together with the high standard deviations (66) and large difference between Min and Max, indicate concentration in the values. Moreover, as the first three quartiles have respectively values 10 , 32 and 78 we can describe the population of universities participating in EU R\&D projects as composed by a large number of institutions with few participations and a small group of institutions involved in a large number of cooperative agreement. Similar observations can be done when we look at the other three variables. Finally, when we compare the descriptive statistics of the total population with the one of participants and non-participants, small positive

20 For humanities and social sciences there exists the specific Social Science SCI which, however, we have not utilized. Thus, these data are biased to the detriment of institutions with humanity or social science department. However, under the first three Framework Programmes only a minor part of the budget was indirectly committed to socio-economic studies, so that we do not consider this a serious weakness for purposes of the present analysis. 
differences are present in the participants' distribution, while important negative differences characterize the non-participants' distribution.

To control for other effects than dimension, scientific research quality and country fixed effects, we have gathered information on the scientific orientation of the university, and on the age -- i.e. period of establishment-- of the universities.

The widespread institutional variety of the European university system has always constrained the value of international comparisons. For example, the Rheinish-Westphalian Technical University in Aachen, Germany has few things in common with the Eindhoven Technical University in Eindhoven, ${ }^{21}$ The Netherlands. The former has faculties like philosophy and education, while the latter is a engineering school. The same kind of diversity can be found between the Italian and the UK Polytechnics. Here we want to suggest a way to classify the different type of European universities. Starting from the fact that the requirements for the doctoral degree are approximately standardised among the EU countries, we have classified the institutions according to the scientific fields in which they grant the Ph.D degree. In particular, taking into account the OECD classification for scientific fields --i.e. Agriculture, Medicine, Natural Sciences, Engineering, Social Sciences and Humanities-- we have created 28 categories. Six for the universities Mono-discipline, which grant the doctoral degree in only one scientific field. All the six classes are relvant. Fifteen for the universities Bi-discipline, which grant the doctoral degree in two scientific fields. Only nine of them include some institutions. Seven for the universities Multi-discipline. In this latter group are included all the institutions that award doctoral degree in three or more scientific fields. To better classify these universities we have controlled for the presence of Engineering, Medicine and Natural Sciences. We have then subdivided the group in seven categories. All of them are relevant.

For each institution we have collected the founding year. Then, we have subdivided this variable in four categories. First, New University (NU, 146 institutions), all the institutions established after 1945. Second, Modern University (MU, 32 institutions), that includes the institutions created between 1900 and 1945. Third, Nineteenth Century University (NCU, 77 institutions), as the name indicates, the ones founded between 1800 and 1900. Finally, Old University (OU, 126 institutions) that includes all the universities that have been founded before 1800.

In the following Section, we shall develop an econometric model that tests the relevance for university participation in EU R\&D projects of: a) the characteristics and behaviour of the universities, b) the behaviour of the funding agency, and c) the un-intended consequences of the

21 The two towns are only 120 kilometres one from the other. 
selection mechanisms. In particular, we shall examine the importance of the following four factors. First, as the large universities tend to have more research groups and, consequently, tend to have more participations in EU R\&D cooperative projects, the dimensional distribution of the total population of European universities influences the skewness of the participations' distribution. Second, the existence of important differences in scientific research quality and the presence of cumulative and self-reinforcement mechanisms can explain why only a small number of universities have a large number of participations. Third, the priorities of the EU research and development policy, especially for what it concerns cohesion policy and technology orientation, determine in a crucial way the frequency of the participations' distribution. Fourth, the diffusion of information about how, were and when to apply for EU funds has taken a relatively long period of time. For some institutions there has been a localization and information advantage, that translated into a "first entry advantage" has enabled the creation of barrier to entry. ${ }^{22}$ Thus, early entrants in the system tend to have a larger number of participations.

\section{An econometric test of the determinants of university participation}

The aim of the regression analysis developed in the following is to test the relevance of dimension, scientific research quality, and other fixed factors on university participation in EU $\mathrm{R} \& \mathrm{D}$ projects. In particular, the analysis of the estimates shall enable to infer the impact on the selection process of the behaviour and characteristics of the universities, the behaviour of the European Commission and the presence of un-intended effect of the selection criteria.

As the number of participations (PART) takes values between 0 and 420, the OLS regression is not a suitable estimation procedure. Two different approaches can be can be used. One is a Tobit model with number of participations as censored dependent variable. The other is two equation model, where the first specification is a Probit model with a binary dependent variable which takes the value 1 when the university has a participation, and 0 when it does not, and the second equation is a Truncated regression model for the non-limit observations --i.e. for the number of participations greater than zero. The advantage of the two equations model is that enables to separate the analysis of the participation or not in a project from the analysis of the multi-participation. The two alternative approaches can be tested against each other. ${ }^{23}$ The double specification can be tested as the unrestricted model against the restricted Tobit model.

\footnotetext{
22 For the discussion of the creation of barrier to entry in the context of selection of publicly founded R\&D project see Geuna (1995; pp.12-14) \{ ME LO LASCI METTERE O PENSI CHE SIA TROPPO !!!! \} For evidences on the phenomena in the UK context see Pike and Charles (1995; pp.20-21)

23 See Cragg (1971) for the original specification of the two equation model.
} 
In the Tobit model (Eq. 1) we regress the dependent variable number of participations (PART) on the independent variables number of researchers (NRES), and ratio between number of publications and number of researchers (RATIO). The first independent variable measures the dimension of the university, while the second is used as a proxy for the scientific research quality of the institution We assume a loglinear relation. Dummy variables (DCOUNTRY) for national fixed effects and control dummy variables (DSCIFIELD) for scientific fields ${ }^{24}$ are included. In the Probit model (Eq. 2) the dependent variable $\mathrm{Y}$ is the probability of being involved in a project, which takes the value 1 when the university has a participation, and 0 when it does not. The same set of independent variables are used. ${ }^{25}$ In the Truncated regression model (Eq. 3) only the universities that have participated in at least one EU R\&D project are considered. The dependent variable $\mathrm{P}$ is the number of participations and is recorded only when it is greater than zero. The independent variables are the ones used in the previous two equations. As in the Tobit model we assume a loglinear relation. The equation (1), (2) and (3) are then formulated as:

(1) $\ln (1-\mathrm{PART})=\alpha+\beta_{1} \ln \mathrm{NRES}+\beta_{2} \ln \mathrm{RATIO}+\sum_{\mathrm{i}=1 . . \mathrm{n}} \beta_{\mathrm{i}} \mathrm{DCOUNTRY}_{\mathrm{i}}+$ $+\sum_{\mathrm{j}=1 . . \mathrm{m}} \beta_{\mathrm{j}}$ DSCIFIELD $_{\mathrm{j}}+\epsilon_{1}$

where $\mathrm{n}=$ number of countries $=10$ and $\mathrm{m}=$ scientific fields categories $=8$.

(2) $\mathrm{Y}=\delta+\gamma_{1} \ln \mathrm{NRES}+\gamma_{2} \ln \mathrm{RATIO}+\sum_{\mathrm{i}=1 . . \mathrm{n}} \gamma_{\mathrm{i}}$ DCOUNTRY $_{\mathrm{i}}+$ $+\sum_{\mathrm{j}=1 . . \mathrm{m}} \gamma_{\mathrm{j}}$ DSCIFIELD $_{\mathrm{j}}+\epsilon_{2}$

where $\mathrm{Y}=1$ if $\mathrm{PART}>0$ and $\mathrm{Y}=0$ if $\mathrm{PART}=0 ; \mathrm{n}=$ number of countries $=9$ and $\mathrm{m}=$ scientific fields categories $=7$.

(3) $\ln (1-\mathrm{P})=\zeta+\mu_{1} \ln \mathrm{NRES}+\mu_{2} \ln \mathrm{RATIO}+\sum_{\mathrm{i}=1 . . \mathrm{n}} \mu_{\mathrm{i}}$ DCOUNTRY $_{\mathrm{i}}+$ $+\sum_{\mathrm{j}=1 . . \mathrm{m}} \mu_{\mathrm{j}}$ DSCIFIELD $_{\mathrm{j}}+\epsilon_{3}$

\footnotetext{
${ }^{24}$ The 8 dummies for scientific fields orientation are the result of a re-categorization of the original classification in 22 classes given by the variable FIELDS.

25 The dummy variables for The Netherlands, Denmark and Natural\&Medicine universities are not included in Eq. 2 because the related universities have always probability 1 .
} 
where $\mathrm{P}$ is observed only when PART $>0 ; \mathrm{n}=$ number of countries $=10$ and $\mathrm{m}=$ scientific fields categories 8 .

Taking equation (1) as the restricted model, and equations (2) and (3) together as the unrestricted model we have used a likelihood ratio test (LLR) to decide which specification we should use. As LLR is equal to 136.66, using a Chi-squared test with 21 degrees of freedom, the Tobit model was rejected at $99 \%$ probability. 
Table 7: Estimation results.

\begin{tabular}{|c|c|c|c|c|c|}
\hline VAR & Tobit & $\begin{array}{c}\text { Restricted } \\
\text { Probit }\end{array}$ & Probit & $\begin{array}{l}\text { Restricted } \\
\text { Truncated }\end{array}$ & Truncated \\
\hline $\mathbf{L} \mathbf{L}$ & -495.46 & -137.08 & -77.18 & -546.72 & -349.95 \\
\hline Constant & $-1.312(.01)^{* *}$ & $1.168(.00)^{* *}$ & $5.333(.88)$ & $3.316(.00)^{* *}$ & $-1.552(.00)^{* *}$ \\
\hline ln NRES & $0.847(.00)^{* *}$ & & $0.197(.19)$ & & $0.888(.00)^{* *}$ \\
\hline In RATIO & $0.560(.00)^{* *}$ & & $0.321(.00)^{* *}$ & & $0.498(.00)^{* * *}$ \\
\hline \multicolumn{6}{|l|}{ DCOUNTRY } \\
\hline Belgium & $0.769(.00)^{* *}$ & & $-3.781(.92)$ & & $0.853(.00)^{* *}$ \\
\hline Denmark & $0.78 \mathrm{E}-1(.84)$ & & - & & $-0.112(.70)$ \\
\hline France & $-0.522(.00)^{* *}$ & & $-3.735(.92)$ & & $-0.646(.00)^{* * *}$ \\
\hline Germany & $-0.809(.00)^{* *}$ & & $-4.356(.90)$ & & $-0.707(.00)^{* * *}$ \\
\hline Greece & $0.706(.01)^{* *}$ & & $-2.595(.94)$ & & $0.293(.20)$ \\
\hline Italy & $-0.457(.02)^{* *}$ & & $-3.435(.92)$ & & $-0.595(.00)^{* * *}$ \\
\hline Ireland & $0.950(.01)^{* *}$ & & $-4.132(.91)$ & & $1.139(.00)^{* *}$ \\
\hline The Netherlands & $-0.18 \mathrm{E}-1(.95)$ & & - & & $-0.283(.25)$ \\
\hline Portugal & $0.312(.29)$ & & $-3.819(.92)$ & & $0.346(.17)$ \\
\hline Spain & $-0.852(.00)^{* *}$ & & $-4.268(.91)$ & & $-0.860(.00)^{* * *}$ \\
\hline United Kingdom & - & & $-3.796(.92)$ & & - \\
\hline \multicolumn{6}{|l|}{ DSCIFIELD } \\
\hline Eng \& Agr & $0.804(.00)^{* *}$ & & $-0.283(.67)$ & & $0.930(.00)^{* *}$ \\
\hline Soc \& Hum & $-0.844(.00)^{* *}$ & & $-1.713(.00)^{* *}$ & & $0.100(.68)$ \\
\hline Nat \& Med & $-0.318(.24)$ & & - & & $-0.313(.13)$ \\
\hline Mix-scientific & $0.46 \mathrm{E}-1(.85)$ & & $-0.320(.61)$ & & $0.90 \mathrm{E}-1(.64)$ \\
\hline Mix-technical & $0.952(.00)^{* *}$ & & $0.41 \mathrm{E}-1(.95)$ & & $0.924(.00)^{* * *}$ \\
\hline Multi-Soc\&Hum & $-0.124(.58)$ & & $-0.836(.11)$ & & $0.87 \mathrm{E}-1(.61)$ \\
\hline Multi-Scientific & $-0.192(.26)$ & & $-0.443(.41)$ & & $-0.137(.29)$ \\
\hline Multi-Technical & $0.305(.101)$ & & $-0.395(.45)$ & & $0.331(.01)^{* * *}$ \\
\hline
\end{tabular}

Non linear Probit. Dependent variable: Binary. Number Obs. 371.

Non linear Truncated regression. Dependent variable: Positive number of participations. Number Obs. 326. Coefficient significance between brackets. Marginal effects have the same significance of coefficients. 
The results of our estimation are shown in Table 7. In the Probit equation ${ }^{26}$ the scientific research quality of the institution has a positive and significant effect on the probability of taking part in a EU R\&D cooperative project. While, the dimension of the university is not significant. None of the dummy variables for country fixed effect have a significant value. Finally, only the dummy that refers to mono-discipline and bi-discipline institutions focused on Social Sciences and Humanities has a negative and significant value. These results highlight that the probability of taking part in a cooperative project financed by the European Commission depends primarily on the scientific research quality of the university. This is consistent with the results of Arora, David and Gambardella (1995), which showed that, in the case of publically-funded R\&D projects, the scientific reputation of the research group, and in particular its weighted number of past publications, is the main factor influencing the probability of being selected. Moreover, these results confirm that the European Commission acted consistently with its stated policy objectives of awarding research founds on grounds of quality. ${ }^{27}$

When we analyse the estimation for the Truncated regression model, important differences in the influence and significance of the explanatory variables are present. Both dimension and scientific research quality have positive and significant coefficients. Consistent with our expectations, the size effect --i.e large universities tend to have more research groups and consequently tend to participate more in EU R\&D projects-- has an important positive impact on the number of participation. Nonetheless, given the dimension, institutions with higher scientific research quality are involved in more projects. Thus, while the probability of being granted depends primarily on the scientific research quality of the university, the participation in $\mathrm{R} \& \mathrm{D}$ projects is effected by the dimension of the institution, and, given its dimension, by its scientific research quality.

Major country fixed effect ${ }^{28}$ are present in the Truncated regression model. They can be subdivided in three sub-groups. First, the dummy variables for France, Germany, Italy and Spain have negative significant values. Given "size" and "quality", the universities of these countries had a lower number of participations. This can be explained looking at the administrative and bureaucratic structure of their national university system. In predominantly public financed systems the novelty of a competitive financing process has constrained the propensity to participate in EU R\&D projects. Although their university systems have a high quality, they are extremely bureaucratic and they are not used to external cooperation and competitive fund raising. Moreover, in particular in the case of France and Italy, a large portion of research is

\footnotetext{
26 The Probit model correctly predicts $90 \%$ of the outcomes.

${ }^{27}$ See for example Commission of the European Communities (1992; p.10).

28 The reference country is United Kingdom
} 
realized in public research organizations --e.g. the CNRS (F), the CNR (I) and other public research centres-- thus the research intensity of the university system tends to be lower than in other countries. Second, the dummy variable for Ireland has positive and significant values. Other factors being equal, this indicates that Irish universities had an advantage in the participation. This advantage is the result of the policy objectives of the European Commission. As we highlighted in Section 2, since the First Framework Programme, technological and economical convergence among the member states of the EU is a major policy aim. Especially from the Third Framework Programme a clear technological cohesion policy has been developed.

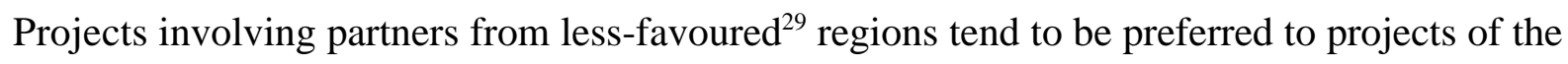
same quality but without member from less-developed regions. Some results show that probably the cohesion policy has also a positive influence on the participation of Greek universities, while the statistical evidence does not support the same conclusion for Portuguese universities. Third, the dummy variable for Belgium has a positive and significant value. This indicates that, given dimension and scientific research quality, Belgian institutions succeeded in having a larger number of participations. A possible explanation is connected with the fact that the diffusion of information about how, were and when to apply for EU funds has taken a relatively long period of time. Thus, Belgian university, exploiting the localization and information advantage, entered early in the system and, consequently, they developed a "first entry advantage" that has enabled the creation of "barrier to entry" to the disadvantage of later comers.

We have used the dummy variable for scientific field to control for the bias inherent in the way we collected the number of publications and to control for the different propensity in publishing. In the chosen specification, the technology oriented institutions have positive and significant values. ${ }^{30}$ The high value of their coefficients, on the top of the control meaning, may also indicate the existence of an advantage for technology oriented universities. However, with the available date, no conclusive observations can be made.

We also tested a set of specification to account for fixed effect from the founding period of the university. We used four dummies for the founding year as proxies for the reputation effect --i.e. the older the university, the higher the reputation. Even if some evidences of a positive coefficient for the modern universities were found, the test for the restricted against the unrestricted specification rejected the latter.

\footnotetext{
${ }^{29}$ In the last Council Regulation 93/2081/EEC Greece, Ireland and Portugal are still included as entire country in the less-favoured regions.

30 We have estimated also other more detailed specifications. The coefficients of the institutions focused on medicine was sometimes significant and negative, indicating the presence of a over-estimation of the scientific research quality of these institutions (see note 19 for the discussion of the reasons). Also due to the small number of institutions with this characteristics, the test for the restricted against unrestricted specification did not allow to reject the null hypothesis. Thus, we chose the 8 dummy specification.
} 
The results of the estimations of the two equation model presented above point to the existence of important difference in the significance of the factors when they are used to explain the probability of joining a EU R\&D project or when they are used to explain the actual number of participations. The quality of the university, and not other factors, influences the probability of participation. The different frequency in participation is, instead, effected by: a) the characteristics and behaviour of the university --e.g. dimension and scientific research quality, bureaucratization and propensity towards competitive fund raising, b) the behaviour of the European Commission --e.g. cohesion policy, and c) the un-intended consequences of the selection mechanisms --e.g. the creation of barriers to entry by early entrants.

\section{Conclusions}

A growing share of the income of European universities is generated through research grants and contracts from both national agencies and the EU. In a context of increasing internationalization of the research process and of rising importance of the research network, the participation in EU R\&D cooperative projects becomes an issue of crucial importance.

This paper is a first attempt to examine in a systematic way the determinants of university participations in EU R\&D projects. In doing this, we studied a original data-set describing the totality of European universities in terms of institutional characteristics and number of participations in projects of the three Framework Programmes of the European Commission. An econometric model was developed to test for the relevance of different factors on both the probability of joining a EU R\&D cooperative project and the actual number of participations in projects.

Some evidence has been found to support the idea that scientific research quality influences both the probability of joining a EU R\&D project and the number of times an institution has participated in projects, while the research dimension has a positive influence only on the latter. Given dimension and scientific research quality of the university, other factors are important to explain the different frequency in participation. First, the bureaucratization and the lack of practice in competitive found raising of the university system may have a negative influence on the propensity to take part in EU R\&D cooperative projects. Second, the existence of techno-economic convergence aims for the Framework Programmes tends to advantage the participation of institutions localized in less-favoured regions. Third, due to the un-intended consequences of the selection mechanisms the early entrance in the system tend to have advantages in the repeated participations. 
Similarly to the results of Gambardella and Garcia-Fontes (1996), our estimations point to the existence of a trade-off in the allocation of research founds. On the one hand, the importance given to the scientific research quality originates, through the effect of cumulative and self-reinforcement mechanisms, a repeated selection of a minority of high research quality institutions. This tends to maximise short-term research outcomes. On the other hand, longer term goals are perused when, following the guidelines of cohesion policy, universities in lessfavoured regions have a priority advantage in the participation. In this way, especially in the case of university research, positive knowledge spillovers may increase the research capabilities of those regions.

Finally, if the consequences of a selection based on the "quality principle" are reinforced by what we called the first entry advantage, a second important trade-off should be consider. On the one hand, the characteristic of repeated selection may tend to reinforce the dominant research strategies (scientific paradigms and research programs), limiting research variety, and consequently decreasing the probability of scientific innovation. ${ }^{31}$ On the other hand, the standardization of scientific knowledge enables an increase communication, and consequently a rise in the value of current science.

In the context of a policy perspective, a better understanding of the two trade-off and of the interactions between them is needed. When more detailed information on the participations is made available by the Commission, a systematic empirical analysis, on the model of the one developed in this paper, will enable to highlight what might be the policy implications of the resource allocation criteria.

\section{References}

Arora, A., David, P.A. and Gambardella, A., 1995, Reputation and Competence in PublicallyFunded Science: Estimating the Effects of Accumulating Knowledge on Research Group Productivity, presented to NBER Summer Workshop on Industrial Organization, Cambridge MA, July.

AXION, 1995, The Impact of EC R\&D Policy on the European Science and Technology Community 1987-1991 $2^{\text {nd }}$ Framework Programme. National Impact Studies Synthesis, Study conducted on behalf of the European Commission, forthcoming.

31 For the discussion of scientific paradigms and research programs see respectively Kuhn (1970) and Lakatos (1970). 
Commission of the European Community, 1994, The European Report on Science and Technology Indicators 1994, Report EUR 15897 EN.

Commission of the European Community, 1992, EC Research Funding. A guide for Applicants.

Cragg, J., 1971, Some Statistical models for Limited Dependent Variables with Application to the Demand for Durable Goods, Econometrica, 39:829-844.

Dasgupta, P. and P.A. David, 1994, Toward a New Economics of Science, Research Policy 23:487-521.

David, P.A., 1994, Positive Feedbacks and Research Productivity in Science: Reopening Another Black Box, in Economics and Technology, O. Granstraad, ed., Amsterdam: Elsevier Science Publishers.

David, P.A., Geuna, A. and W.E. Steinmueller, 1995, Additionality as a Principle of European $R \& D$ Funding, A Study carried out for the STOA Programme of the European Parliament, MERIT's Research Memoranda 2/95-012.

Geuna, A., 1995, University Participation in Community Programmes: How Does the Selection Process Work?, MERIT's Research Memoranda 2/95-002.

International Association of Universities, 1991, 1994, International Handbook of Universities, Stockton Press.

Kuhn, T.S., 1970, The structure of Scientific Revolutions, 2nd ed., University of Chicago Press, Chicago.

Lakatos, I., Falsification and the Methodology of Scientific Research Programmes, in Criticism and the Growth of Knowledge, I. Lakatos and A. Musgrave, eds., Cambridge University Press, Cambridge.

Luukkonen, T., O. Persson and G. Sivertsen, 1992, Understanding Patterns of International Scientific Collaboration, Science, Technology, \& Human Values, Vol. 17, No.1, pp.101-126.

Malerba, F. et. al., 1991, The Nascent Globalization of Universities and Public and Quasi-Public Research Organizations, FAST Research in the Framework of the MONITOR Programme. 
Pike, A. And D. Charles, 1995, The impact of International Collaboration on UK UniversityIndustry Links, Industry and Higher Education, August 1995.

World of Learning, 1995, Europa Publications, London.

Universities' Statistical Record, University Statistics. Vol. 3 Finance, Various Years. 
